\title{
COMPETITIVIDAD DE LAS EXPORTACIONES ARGENTINAS DE QUESOS Y LECHE EN POLVO: UN ANÁLISIS A PARTIR DE LA DEMANDA EXTERNA DE LOS PRINCIPALES IMPORTADORES $^{\circ \wedge}$
}

\author{
COMPETITIVENESS OF ARGENTINE CHEESE AND MILK \\ POWDER EXPORTS: A DEMAND ANALYSIS OF THE MAIN \\ IMPORTER COUNTRIES
}

\author{
Mariano Nicolás Coronel* \\ Rodrigo García Arancibia** \\ Jimena Vicentín Masaro ${ }^{* * *}$
}

enviado: 03 febrero 2021 - aprobado: 03 junio de 2021

\begin{abstract}
Resumen
El mercado externo resulta crucial para el crecimiento competitivo del sector lácteo argentino. Con una demanda mundial cambiante, el sector ha logrado adaptarse e insertarse en nuevos mercados, aunque con un desempeño competitivo muy volátil. Dada la relevancia de estas condiciones de demanda para la competitividad del sector, en el presente trabajo se estudia el posicionamiento de las exportaciones argentinas de quesos y leche en polvo entera mediante un análisis de la demanda en

\footnotetext{
Una versión preliminar del trabajo fue presentada en la Reunión Anual de la Asociación Argentina de Economía Araria (AAEA) en octubre del 2020. Trabajo realizado en el marco del CAID-UNL 2016 (Cod. 50020150100094LI). ciones argentinas de quesos y leche en polvo: un análisis a partir de la demanda externa de los principales importadores. Estudios económicos, 39(78), pp. 187-221. DOI: https://doi.org/10.52292/j. estudecon.2022.2350 Litoral, Argentina. ORCID: https://orcid.org/0000-0003-0847-8255. Correo electrónico: mcoronel@ fce.unl.edu.ar del Litoral y CONICET, Argentina. ORCID: https://orcid.org/0000-0003-3999-2097. Correo electrónico: rgarcia@fce.unl.edu.ar
}

^ Coronel, M. N., García Arancibia, R., \& Vicentín Masaro, J. (2022). Competitividad de las exporta-

* Instituto de Economía Aplicada Litoral, Facultad de Ciencias Económicas, Universidad Nacional del

** Instituto de Economía Aplicada Litoral, Facultad de Ciencias Económicas, Universidad Nacional
\end{abstract}


los principales mercados importadores basado en el enfoque diferencial de la teoría de la producción. Se computan las elasticidades gasto, precio-propias y preciocruzadas de los lácteos argentinos y de sus competidores; y a partir de dos índices de competitividad se describe las posibilidades competitivas en el mercado de importaciones lácteas.

Palabras clave: enfoque diferencial, demanda de insumos, elasticidades, sector lácteo, comercio internacional.

Clasificación JEL: F14, D51.

\begin{abstract}
The international trade is crucial to the Argentine dairy sector competitive growth. With a changing world demand, this sector has adapted and introduced in new markets, but with a volatile performance. Owing to the relevance of this demand conditions to the competitiveness of the sector, this paper studies the positioning of Argentine exports of cheese and whole milk powder using a demand analysis in the main importing markets based on the differential approach of the theory of production. The expenditure, own-price and cross-price elasticities of Argentine dairy products and their competitors are computed; and it is describe the competitive possibilities in the dairy import market by two competitiveness indices.
\end{abstract}

Keywords: differential approach, input demand, elasticities, dairy sector, international trade.

JEL Codes: F14, D51. 


\section{INTRODUCCIÓN}

Si bien en los últimos 20 años las exportaciones lácteas argentinas han mostrado una tendencia creciente tanto en cantidad como en valor, la evolución ha sido más bien errática, con períodos de fuertes incrementos en volúmenes y valores, como así también caídas sustanciales de los mismos, que han terminado deteriorando el posicionamiento competitivo del sector (García Arancibia, Depetris Guiguet, Vicentin Masaro \& Rossini, 2013, p. 73). Estas fluctuaciones se han dado por diversos factores, tales como aquellos relacionados con variaciones en precios internacionales, cambios de políticas comerciales en torno a las exportaciones, shocks climáticos internos y cambios de la demanda externa. En este contexto dinámico volátil e incierto, el sector lácteo argentino supo mantener su posicionamiento competitivo en sus principales mercados internacionales, con predominio de la leche en polvo y los quesos. Al mismo tiempo supo adaptarse a tales cambios, incorporando nuevos e importantes compradores en el escenario alimentario global (García Arancibia, 2017, p. 277).

A pesar de que las exportaciones lácteas representen aproximadamente solo el $20 \%$ de los litros industrializados por el país, la demanda internacional resulta crucial para la competitividad global del sector, no solo por las limitaciones naturales que existen en el crecimiento de la demanda doméstica (y con ello, del tamaño potencial del mercado), sino también por su rol crucial en la determinación de precios de la cadena (Rossini, Vicentin Masaro, García Arancibia \& Coronel, 2013, p. 153; Vicentin Masaro, Depetris, García Arancibia \& Rossini, 2013, p. 19).

La leche en polvo constituye el principal bien exportable del sector lácteo, representando en promedio más del $40 \%$ del valor total de las exportaciones del sector. En particular, la leche en polvo entera (LPE) supera el 36\% del total, con un crecimiento casi continuo de los valores y volúmenes exportados hasta 2014, mostrando luego una fuerte caída debido a la disminución de los precios internacionales, recuperándose y estancándose a partir de 2017 a niveles inferiores a los de 2010 (Observatorio de la Cadena Láctea Argentina [OCLA], 2020). Los principales destinos de la LPE han sido, históricamente, Argelia y Brasil, pero también existen otros destinos relevantes, en los cuales Argentina participa de forma continuada y con una significativa participación en el mercado, como ser Chile, Paraguay, Perú, Níger y Senegal, entre otros.

Por otra parte, las exportaciones de quesos experimentaron un gran crecimiento en los últimos 20 años, lo que fue acompañado por una diversificación de los tipos de quesos comercializados, con una fuerte expansión de la mozzarella, 
que ha ganado participación en destinos no tradicionales como ser Rusia, Japón, Corea del Sur y Taiwán (Depetris Guiguet, Rossini, García Arancibia \& Vicentin Masaro, 2011, p. 155). El mayor impulso de las exportaciones se dio en el período posdevaluatorio, luego de atravesar la crisis de 2001-2002, con un crecimiento anual en las cantidades y valores exportados superior al 50\% en 2004 y 2005. Esto implicó también una mayor participación de los quesos en las exportaciones lácteas totales, superando el $20 \%$ del total para estos años. Alcanzado un pico en 2006, ya para 2007-2008 las exportaciones comienzan a declinar a pesar del incremento experimentado en los precios internacionales. Justamente en tal período existe una mayor intervención gubernamental, con una política de retenciones, precios de corte y demoras en autorizaciones para exportar, haciendo menguar los volúmenes comerciados, y generando incentivos para un cambio de estrategia hacia la mozzarella y los quesos semiduros en detrimento de los quesos duros que históricamente tenían la mayor participación (Depetris Guiguet et al., 2011, p. 149). En 2011 existe un boom de precios que hace incrementar el valor total de las exportaciones queseras en un 50\%, para luego estabilizarse, convergiendo a los volúmenes exportados del período 2004-2006 (Coronel et al., 2020, p. 3). Actualmente, las exportaciones de quesos superan al 20\% del valor total de exportaciones lácteas (OCLA, 2020).

Ante este escenario histórico tan cambiante, la industria láctea ha mostrado capacidad de adaptarse al mercado mundial, diversificando su oferta e incrementando su participación en mercados no convencionales. Mantener y ganar posicionamiento en los mercados internacionales requiere de acertadas decisiones productivas y estratégicas de los exportadores. En este sentido, el conocimiento del grado de respuesta de la demanda de los países compradores ante cambios en los precios relativos de los diferentes oferentes, puede ser crucial al momento de diseñar estrategias competitivas por parte de las firmas y del sector gubernamental en pos de posicionar al país como un importante oferente en el escenario mundial y con ello fortalecer el desempeño sectorial.

Existe una vasta literatura donde se analiza la evolución competitiva del sector lácteo argentino, ponderando la importancia de la demanda internacional como factor clave de la competitividad (e. g. Depetris Guiguet et al., 2009; 2011; 2012; entre otros). En otra línea, algunos trabajos proponen modelos explicativos para analizar la oferta exportable de la producción láctea, pero sin ahondar sobre el comportamiento de los países demandantes (García Arancibia et al., 2013; Depetris Guiguet et al., 2013; Coronel et al., 2014). Por el lado de la demanda de productos lácteos, una serie de investigaciones han estimado las elasticidades de la demanda doméstica de productos lácteos (e.g. Lema et al., 2005; Rossini et al., 2008). Respecto a la demanda externa, 
desde un enfoque de sistemas de demanda de importaciones, García Arancibia (2019) y García Arancibia y Depetris Guiguet (2020) estiman las elasticidades de demanda para leche en polvo y quesos de Chile y Brasil, respectivamente, construyendo indicadores de competitividad basados en tales elasticidades. Bajo una perspectiva más global, García Arancibia (2017) y García Arancibia et al. (2015), en un enfoque uniecuacional para datos de panel, estima la demanda de los principales compradores mundiales de lácteos argentinos ante variaciones en los precios relativos y demás variables que afectan al comercio. En estos trabajos, las ecuaciones de demanda se derivan a partir de la teoría del consumidor, donde la demanda de los países importadores surge de maximizar una función de utilidad del importador sujeto a su respectiva restricción presupuestaria. En el presente trabajo se propone un modelo para estimar las elasticidades de demanda de LPE y de quesos, pero, contrariamente a los enfoques anteriores, se aborda el problema desde la teoría microeconómica del productor con una especificación flexible basada en el denominado enfoque diferencial adaptado para datos de panel (Laitinen, 1980; Laitinen y Theil, 1978). De esta manera, en contraste a los enfoques basados en la teoría del consumidor, se está suponiendo que los países importadores demandan como insumos las importaciones lácteas, las cuales precisan de algún proceso de empaquetamiento, distribución y comercialización, para llegar al consumidor final de dicho país. Con este trabajo se busca contribuir a la literatura ya existente de demanda internacional de lácteos argentinos, con una propuesta teórica y metodológica diferente, proponiendo un modelo flexible y simple de estimar en cuanto al método y al uso de datos, del cual pueden obtenerse estimaciones de elasticidades de demanda de los principales países importadores, y con ello indicadores de posicionamiento competitivo de Argentina en los mercados internacionales frente a sus competidores, uno general y otro por destinos de las exportaciones.

La teoría microeconómica de la producción ha sido extensamente utilizada para el estudio de la demanda de importaciones. Así, por ejemplo, Koo, Mao y Sakurai (2001) estudian la demanda de importaciones de trigo de Japón adoptando una función de costos translogarítmica. Por su parte, bajo el enfoque diferencial, Washington, Yigletu y Andrews (2012) estudiaron la demanda de importaciones de trigo en Ghana; Washington y Kilmer (2002a, 2002b), las importaciones de lactosuero y quesos en Japón, respectivamente; Muhammad, Amponsah y Dennis (2010), las importaciones de flores en la Unión Europea, en tanto qe Muhammad (2009) se ha enfocado a las rosas provenientes de países africanos; Muhammad (2007) analizó las importaciones de pescado en la Unión Europea; Muhammad, Jones y Hahn (2007), la demanda de importaciones de carne de cordero en Estados Unidos; y Wang y Reed (2014), para Estados Unidos, estimaron la demanda de importaciones de camarón diferenciados por origen. 
Lo que resta del presente trabajo se estructura de la siguiente manera. En la próxima sección, se plantea el marco teórico sobre el que se derivan las demandas de importaciones en mercados en los que participa Argentina. Luego se presenta el modelo econométrico, los datos y la metodología llevada a cabo para su estimación, como así también la derivación de las elasticidades de interés. En la sección 4 se realiza un análisis descriptivo de la participación argentina en los mercados importadores. Posteriormente, se presentan los resultados de la estimación de las demandas y sus elasticidades, finalizando la sección de resultados con un análisis de indicadores de competitividad basados en el comportamiento de la demanda. Se finaliza con unas breves conclusiones.

\section{MARCO TEÓRICO}

Para racionalizar la demanda internacional de lácteos argentinos, se toma como punto de partida la hipótesis de Armington (1969), bajo la cual los bienes importados con diferentes orígenes, i. e. exportados por diferentes países o regiones, son percibidos como diferenciados por parte del país importador. Por lo tanto, cuando un país importa un bien del resto del mundo, el mismo ya es diferenciado por el solo hecho de tener un país de origen distinto. Esta hipótesis general puede ser adoptada tanto cuando se considera la demanda de producto final desde el enfoque de la teoría del consumidor (e. g. García Arancibia, 2017), como cuando se toma la demanda de insumo desde la teoría de la producción. Bajo el enfoque diferencial de producción, las firmas importadoras determinan en la primera etapa la cantidad a producir del bien final que maximiza sus beneficios, y en la segunda etapa, minimizan el costo de producir dicha cantidad (Laitinen, 1980; Laitinen $\&$ Theil, 1978). De la segunda etapa y para un importador particular, se deriva el sistema de demanda diferenciado por origen $i$, que viene dado por

$$
f_{i} d\left(\ln x_{i}\right)=\theta_{i} d(\ln X)+\sum_{k=1}^{M} \pi_{i k} d\left(\ln p_{k}\right),
$$

donde $f_{i}$ representa la participación del exportador $i$ en las importaciones totales del país importador con $i=1,2, \ldots, M$, , i. e. $f_{i} \frac{p_{i} x_{i}}{\sum_{i=1}^{M} p_{i} x_{i}}$, donde $x_{i}$ y $p_{i}$ son las cantidades y precio de importación del país de origen $i$; $p_{k}$ es el precio de importación del país de origen $k$ con $k=1,2, \ldots, M ; d(\ln X)=\sum_{i=1}^{M} f_{i} d\left(\ln x_{i}\right)$ representa el "Índice Divisia"1 para las importaciones totales, siendo $\ln ($.$) el$

1 Introducido en 1925 por François Divisia como índice para representar el cambio (continuo) de variables económicas que pueden estar expresadas en diferentes unidades de medida. 
logaritmo neperiano; y por último, $\theta_{i}$ y $\pi_{i j}$ representan los parámetros del modelo. Para que el modelo propuesto sea consistente con las hipótesis que se desprenden de la teoría microeconómica, se requiere el cumplimiento de las siguientes propiedades:

a. Aditividad: $\sum_{i=1}^{M} \theta_{i}=1$ y $\sum_{i=1}^{M} \pi_{i k}=0$,

b. Homogeneidad: $\sum_{k=1}^{M} \pi_{i k}=0$,

c. Simetría: $\pi_{i k}=\pi_{k i} \forall i, k$,

d. Concavidad de la función de costos: matriz de coeficientes asociados a los $M$ precios, i.e.

$$
\left(\begin{array}{ccc}
\pi_{11} & \ldots & \pi_{1 M} \\
\vdots & \ddots & \vdots \\
\pi_{M 1} & \ldots & \pi_{M M}
\end{array}\right) \text { debe ser semi-definida negativa. }
$$

En el presente trabajo y siguiendo a García Arancibia (2018), se considera como orígenes de las importaciones de LPE y quesos por parte del país $j$, con $j=1,2, \ldots, N$, a las provenientes de Argentina por un lado, y a las provenientes de los países competidores por otro, que son agrupados bajo Competidores, por lo que el sistema de demanda está conformado por dos ecuaciones. Ahora bien, la condición de aditividad implica que el sistema de demanda es singular, por lo que una de las dos ecuaciones es combinación lineal de la otra. Por ende, y para el caso particular en que $M=2$, es suficiente la consideración de una sola ecuación para estimar el conjunto de parámetros del modelo.

Finalmente, asumiendo que las funciones de producción son equivalentes para los $j$ países importadores, el modelo teórico propuesto para estimar las elasticidades de la demanda de importaciones de LPE y quesos de origen argentino se representa por la siguiente ecuación

$$
f_{a, j t} d\left(\ln x_{a, j t}\right)=\theta_{a} d\left(\ln X_{j t}\right)+\pi_{a a} d\left(\ln p_{a, j t}\right)+\pi_{a c} d\left(\ln p_{c, j t}\right)
$$

donde $j$ indexa a los países importadores, $t$ al tiempo y los subíndices $a$ y $c$ representan a Argentina y sus competidores, respectivamente. El supuesto de una 
tecnología de producción equivalente entre países importadores implica que los parámetros $\theta_{a}, \pi_{a a}$ y $\pi_{a c}$ son los mismos para todos ellos, permitiendo la formulación del modelo (2). Si bien dicho supuesto aparece como demasiado restrictivo respecto a la conducta de los agentes que se intenta modelar, la principal justificación es de naturaleza empírica, ya que radica en la imposibilidad de contar con variables con una frecuencia menor a la anual para la mayoría de los países importadores de LPE y quesos. Esta estrategia permite la obtención de estimaciones de los parámetros mediante la utilización de datos en panel, que deben ser interpretadas como la respuesta o comportamiento "promedio" de los países importadores.

Si bien los parámetros $\theta_{a}, \pi_{a a}$ y $\pi_{a c}$ se suponen equivalentes para todos los importadores, las elasticidades de demanda pueden variar en función de la participación de cada origen en el total importado. De esta forma, las elasticidades precio, propia y cruzada, de la demanda de importaciones de origen argentino para el país importador $j$ vienen dadas por

$$
\eta_{a, p_{a}}^{j}=\frac{d\left(\ln x_{a, j}\right)}{d\left(\ln p_{a, j}\right)}=\frac{\pi_{a a}}{f_{a, j}} \quad y \eta_{a, p_{c}}^{j}=\frac{d\left(\ln x_{a, j}\right)}{d\left(\ln p_{c, j}\right)}=\frac{\pi_{a c}}{f_{a, j}},
$$

respectivamente, mientras que la elasticidad de la demanda respecto a las cantidades totales importadas por el país $j$ se calcula como

$$
\eta_{a, X}^{j}=\frac{d\left(\ln x_{a, j}\right)}{d\left(\ln X_{j}\right)}=\frac{\theta_{a}}{f_{a, j}}
$$

Otra alternativa que puede plantearse a partir del modelo (2), y que implica un menor grado de restricción sobre la conducta de los países importadores, consiste en la incorporación de un término de interacción que permite analizar la respuesta de manera diferenciada. De esta forma, pueden clasificarse a los países en grupos relativamente homogéneos, y diferenciar así la respuesta en función de esas categorizaciones. Si se clasifican los países en dos grupos, la extensión del modelo (2) viene dada por

$$
\begin{aligned}
f_{a, j t} d\left(\ln x_{a, j t}\right)= & \theta_{a} d\left(\ln X_{j t}\right)+\tilde{\theta}_{a} G 1_{j} \times d\left(\ln X_{j t}\right)+ \\
+ & \pi_{a a} d\left(\ln p_{a, j t}\right)+\tilde{\pi}_{a a} G 1_{j} \times d\left(\ln p_{a, j t}\right)+ \\
& +\pi_{a c} d\left(\ln p_{c, j t}\right)+\tilde{\pi}_{a c} G 1_{j} \times d\left(\ln p_{c, j t}\right),
\end{aligned}
$$


donde $G 1_{j}$ representa una variable dicotómica que toma el valor 1 si el país $j$ pertenece al grupo 1 y 0 en caso contrario, es decir, si $j$ pertenece al grupo 2 . Las elasticidades precio, propia y cruzada, de la demanda de importaciones de origen argentino de los países del grupo 1 vienen dadas por

$$
\begin{aligned}
\eta_{a, p_{a}}^{G 1}= & \frac{d\left(\ln x_{a, G 1}\right)}{d\left(\ln p_{a, G 1}\right)}=\frac{\pi_{a a}+\tilde{\pi}_{a a}}{f_{a, G 1}} y \\
\eta_{a, p_{c}}^{G 1}= & \frac{d\left(\ln x_{a, G 1}\right)}{d\left(\ln p_{c, G 1}\right)}=\frac{\pi_{a c}+\tilde{\pi}_{a c}}{f_{a, G 1}},
\end{aligned}
$$

respectivamente, mientras que la elasticidad de la demanda respecto a las cantidades totales importadas por el grupo 1 se calcula como

$$
\eta_{a, X}^{G 1}=\frac{d\left(\ln x_{a, G 1}\right)}{d\left(\ln X_{G 1}\right)}=\frac{\theta_{a}+\tilde{\theta}_{a}}{f_{a, G 1}} .
$$

Las elasticidades de la demanda de importaciones de los países del grupo 2 resultan equivalentes a (3) y (4), ya que se toma este grupo como la categoría base, i. e. $G 1=0$.

\section{METODOLOGÍA}

\section{II.1. Especificación econométrica}

Como fuera planteado anteriormente, el modelo teórico (2) es propuesto con el fin de estimar el mismo a partir de una estructura de datos en panel o longitudinales, compuesta por los $j$ países importadores de LPE por un lado, y quesos por otro, a través de un período de $T$ años. Por ende, la especificación econométrica del modelo (2) está dada por

$$
\begin{gathered}
\bar{f}_{a, j t} \Delta x_{a, j t}=\theta_{a} \Delta X_{j t}+\pi_{a a} \Delta p_{a, j t}+\pi_{a c} \Delta p_{c, j t}+\varepsilon_{j t} \\
\text { donde } \bar{f}_{a, j t}=\frac{\left(f_{a, j t}+f_{a, j t-1}\right)}{2} ; \Delta x_{a, j t}=\ln \left(\frac{x_{a, j t}}{x_{a, j t-1}}\right) \text { y } \Delta p_{c, j t}=\ln \left(\frac{p_{c, j t}}{p_{c, j t-1}}\right),
\end{gathered}
$$


representan las variaciones discretas de las variables del modelo diferencial, mientras que $\varepsilon_{j t}$ corresponde al término de error del modelo econométrico. De la misma forma, la contrapartida discreta del "Índice Divisia" se construye como

$$
\Delta X_{j t}=\bar{f}_{a, j t} \Delta x_{a, j t}+\bar{f}_{c, j t} \Delta x_{c, j t} .
$$

Con el objeto de flexibilizar el modelo (8) sin incrementar sensiblemente el número de parámetros a estimar, se clasifican en 2 grupos a los $j$ países importadores, tanto de quesos como de leche en polvo, teniendo en cuenta principalmente la participación que posee Argentina en cada uno de esos mercados. Con esto se busca clasificar a los países importadores en dos grupos con características disímiles, pero que al interior de los mismos cuenten con un comportamiento similar como demandantes de LPE y quesos. A su vez, esta separación en subgrupos de importadores flexibiliza de cierta manera el supuesto de una tecnología de producción equivalente. Con ello ahora se estaría suponiendo que el nivel de participación que tiene Argentina revelaría de alguna manera conjuntos de importadores lácteos relativamente homogéneos en términos de la forma en que transforma la importación láctea vía una determinada función de producción. Si bien este supuesto sigue siendo fuerte, el mismo permite obtener modelos parsimoniosos sin perder de eje que se busca una medición del comportamiento promedio de los mercados internacionales semejantes.

Para las exportaciones de queso, se cuenta con 13 países importadores relevantes (i.e. excluyendo aquellos que realizan compras esporádicas o muy discontinuadas) durante el período analizado, que son clasificados en dos grupos teniendo en cuenta la participación media de Argentina en las importaciones totales. El primero, denominado PA (Participación Alta), está compuesto por Bolivia, Brasil, Chile, Paraguay, Perú y Uruguay, en los cuales Argentina posee una participación promedio superior al 15\%. El segundo grupo, denominado PB (Participación Baja), está conformado por Corea del Sur, Estados Unidos, Japón, Marruecos, Méjico, Rusia y Venezuela, donde la participación de Argentina no supera el 15\% del total.

En el caso de la LPE, son 12 los países importadores que se consideran en este estudio. Siguiendo similar estrategia de clasificación y denominación que en quesos, el primer grupo está compuesto por Argelia, Bolivia, Brasil, Chile, Níger y Paraguay (grupo $P A$ ), mientras que el segundo lo componen Congo, Costa de Marfil, Líbano, México, Perú y Senegal (grupo PB). Adicionalmente, introducimos una variable dummy para indicar la medida de salvaguardia del año 
2007 que fue impuesta por Chile de forma exclusiva a los lácteos provenientes de Argentina. Como bien muestra García Arancibia (2019), esta medida tuvo un impacto significativo sobre las importaciones chilenas de LPE y quesos argentinos. De esta forma, el modelo econométrico para analizar la demanda de importaciones de ambos productos viene dado por

$$
\begin{gathered}
\bar{f}_{a, j t} \Delta x_{a, j t}=\theta_{a} \Delta X_{j t}+\pi_{a a} \Delta p_{a, j t}+\pi_{a c} \Delta p_{c, j t}+\delta \text { chile }_{j t}+ \\
+\tilde{\theta}_{a} P A_{j} \times \Delta X_{j t}+\tilde{\pi}_{a a} P A_{j} \times \Delta p_{a, j t}+ \\
+\tilde{\pi}_{a c} P A_{j} \times \Delta p_{c, j t}+\varepsilon_{j t}
\end{gathered}
$$

donde chile $_{j t}$ representa una variable dicotómica que toma el valor 1 para la observación correspondiente a Chile en el año 2007, año durante el cual estuvo vigente la medida de salvaguarda y $P A_{j}$ es una variable dicotómica que toma el valor 1 si el país $j$ pertenece al grupo $P A, \mathrm{y} 0$ en caso contrario, i. e. $j \in P B$. De esta forma, si al menos uno de los términos $\tilde{\theta}_{a}, \tilde{\pi}_{a a}$ y $\tilde{\pi}_{a c}$ resulta distinto de cero, implica una conducta diferente entre ambos grupos de países.

\section{II.2. Datos y estimación}

Para la estimación de los parámetros se utilizan convencionalmente los modelos Agrupado, de Efectos Fijos y de Efectos Aleatorios. Los dos últimos se diferencian del primero ya que contemplan, bajo distintos supuestos, la existencia de heterogeneidad no observada entre los países importadores. Sin embargo, por la propia construcción del modelo y la formulación de las variables en primeras diferencias, la heterogeneidad individual, $i$. e. todos aquellos factores no observables e invariantes en el tiempo, es controlada per se. Por lo tanto, se escoge estimar el modelo Agrupado, es decir, sin considerar el efecto individual, mediante el estimador de Mínimos Cuadrados Ordinarios (MCO), y luego corregir sus errores estándar.

El hecho de contar con un sistema de dos ecuaciones facilita la prueba de las restricciones de homogeneidad y simetría en precios, ya que en este caso, el cumplimiento de una condición implica el cumplimiento de la otra. El modelo (10) se estima mediante MCO y se contrasta luego la hipótesis nula de homogeneidad y simetría para cada uno de los grupos, i. e. $H_{0}: \pi_{a a}-\pi_{a c}=0$ para el grupo $P B$ y $H_{0}:\left(\pi_{a a}+\tilde{\pi}_{a a}\right)-\left(\pi_{a c}+\tilde{\pi}_{a c}\right)=0$ para el grupo $P A$. Alternativamente, puede calcularse también el test del cociente de verosimilitud al estimar el modelo (10) 
mediante Máxima Verosimilitud sin restricciones e imponiendo la condición de homogeneidad y simetría. El mismo viene dado por $2\left[l^{L}-l^{R}\right]$ donde $l^{L}$ representa el logaritmo neperiano de la verosimilitud bajo el modelo libre y $l^{R}$ el logaritmo neperiano de la verosimilitud bajo el modelo imponiendo homogeneidad. Bajo $H_{0}$ dicho test se distribuye como una Chi cuadrado con un grado de libertad (diferencia de parámetros libres entre los modelos comparados).

Los restantes parámetros del modelo son recuperados a partir de las condiciones de aditividad, homogeneidad y simetría. El supuesto de concavidad de la función de costos puede analizarse a partir de los menores principales o valores propios de la matriz de coeficientes asociados a los precios. Por último, las elasticidades son evaluadas en la mediana y sus errores estándar se computan mediante el método Delta.

Los datos son obtenidos de COMTRADE y FAOSTAT, conformándose para la demanda de quesos y leche en polvo un panel de 13 y 12 países respectivamente, durante el período 2003-2018.

\section{II.3. Indicadores de competitividad}

Una vez estimadas las ecuaciones de demanda y computadas las elasticidades respectivas de acuerdo a las ecuaciones (3), (4), (6) y (7), es posible construir indicadores de competitividad basados en el comportamiento de la demanda externa, partiendo de una medida proxy del grado de competencia, y con ello del posicionamiento competitivo de Argentina. Específicamente, para un destino $j$ se define el siguiente índice de posicionamiento competitivo de Argentina en el país $j$ de la forma

$$
I C_{a, j}=\frac{\bar{f}_{a, j}}{\left|\eta_{a a, j}\right|}
$$

donde $\bar{f}_{a, j}$ representa la participación media de Argentina en el destino, $j \in J$, y $\eta_{a a, j}$ es la elasticidad precio propia de la demanda de quesos o LPE de Argentina en los países incluidos en $j$, con $J=P A, P B$. Este índice es una medida aproximada del poder de mercado que revela Argentina en un cierto país comprador, y es un indicador de competitividad refinado respecto a la simple participación en el mercado mundial, al incorporar la respuesta de la demanda en la fijación de los precios propios. Bajo ciertos supuestos, el $I C_{a, j}$ constituye una 
proxy del denominado índice de Lerner, $\left(p_{a}^{j}-c_{a}^{j}\right) / p_{a}^{j} \propto \bar{f}_{a, j} /\left|\eta_{a a, j}\right|$ (e.g. Kaiser $\&$ Suzuki, 2006). Siguiendo a García Arancibia (2017), aquí se lo toma como un índice del posicionamiento competitivo que tiene en los mercados internacionales, pues el mismo es creciente cuando el país tiene una participación alta en un mercado más insensible ante cambios en los precios propios, revelando así una mayor potencialidad para mantener e incrementar sus ventas en dicho mercado.

En la misma línea, si se considera el rol de la concentración del mercado en la competencia en dicho mercado, puede plantearse para cada conjunto de países el siguiente índice de competitividad general:

$$
I C G=\frac{I H H_{j}}{\left|\eta_{a a, j}\right|}
$$

donde $\mathrm{IHH}_{j}$ se calcula como la media del índice de Hirschman-Herfindahl en cada uno de los países del grupo $j$. De esta manera, a mayor concentración (i. e. mayor $I H H)$ y menor elasticidad, mayor facilidad para los exportadores de mantener su posición en el mercado sin recurrir a una mayor rivalidad competitiva en precios. Para este último indicador, se realiza un análisis en el tiempo a fin de visualizar la evolución de las posibilidades competitivas de Argentina en tales mercados.

\section{LA PARTICIPACIÓN DE ARGENTINA EN LA DEMANDA MUNDIAL DE LECHE EN POLVO Y QUESOS}

Antes de analizar los resultados de la estimación de las demandas de importaciones y de sus elasticidades, exponemos una descripción de la evolución de Argentina en términos de su participación en los principales mercados internacionales seleccionados. En la figura 1 se muestra la evolución de la participación de Argentina en el total importado en cada uno de los países demandantes de quesos y, en la figura 2, de los países demandantes de LPE. Se observa que Argentina tiene, casi todo el período, una participación mayor al $68 \%$ en las importaciones de quesos de Paraguay, con una relativa estabilidad en dicha participación. Por su parte, los quesos argentinos han incrementado su participación en las importaciones totales de este producto en Uruguay y Brasil, pasando de representar el $15 \%$ y $38 \%$, al $45 \%$ y $60 \%$, respectivamente. Por otro lado, la participación de Argentina en las importaciones de quesos de Chile ha tenido una tendencia decreciente. 
Dentro del grupo de países demandantes de quesos donde la participación de Argentina es baja (figura 1b), la importancia relativa de este último ha mostrado una caída en casi todos, excepto en el caso de Rusia. Se observa que este país a partir de 2013 ha incrementado las importaciones de quesos desde Argentina, con máxima participación en 2015. Rusia pasó de importar 507 toneladas de quesos en 2003, a más de 11300 toneladas en 2018, por un valor de 55 millones de dólares.

En términos absolutos, Brasil es el mayor importador de quesos argentinos dentro del grupo de países importadores considerados: demanda de Argentina más de 11000 toneladas de quesos en promedio, por un valor de 48 millones de dólares. Bolivia, por su parte, es el país con las menores importaciones de quesos desde Argentina, en promedio demanda 187 toneladas.

Se destaca el caso de Venezuela, donde las importaciones de quesos desde Argentina se volvieron muy relevantes a partir de 2008. Los quesos de origen argentino llegaron a representar casi el $16 \%$ del total importado por este país en 2010, importando 2705 toneladas a un valor de 18 millones de dólares. Se desconoce cómo ha sido la evolución después de 2013, ya que se discontinúa la serie.

Respecto a la LPE, también Paraguay tiene como principal origen de sus importaciones de este producto a la Argentina, pero con tendencia negativa: pasó de tener una participación casi exclusiva entre 2003-2007 a menos del 50\% en 2018, con caída de la participación desde 2015. Sin embargo, las cantidades importadas de este país no superan en promedio las 1100 toneladas por un valor de poco más a 3 millones de dólares.

La importancia relativa de la LPE Argentina en casi todos los países considerados ha tenido una tendencia decreciente, excepto Argelia y Chile, donde Argentina participa en promedio un $20 \%$ y $53 \%$, respectivamente, en el total de LPE importado de estos países (figura 2). Las importaciones de Argelia son, en promedio, de casi 34 mil toneladas y, dentro del grupo es el que mayor importaciones de LPE desde Argentina realiza, por un valor promedio de 122 millones de dólares. 
Figura 1. Evolución de la participación de Argentina en los mercados importadores de quesos

(a)

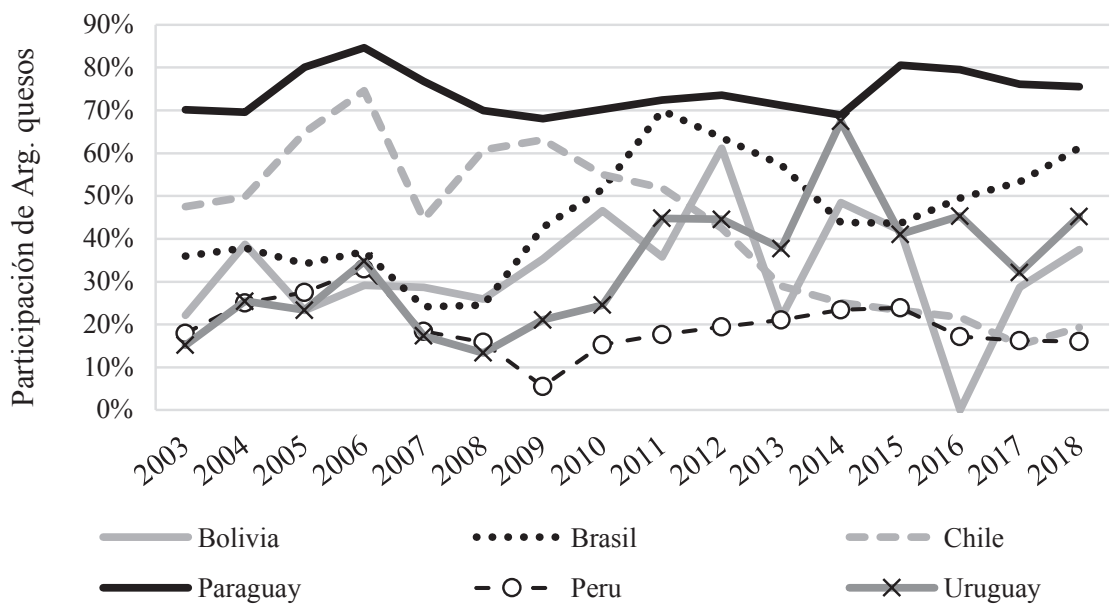

(b)

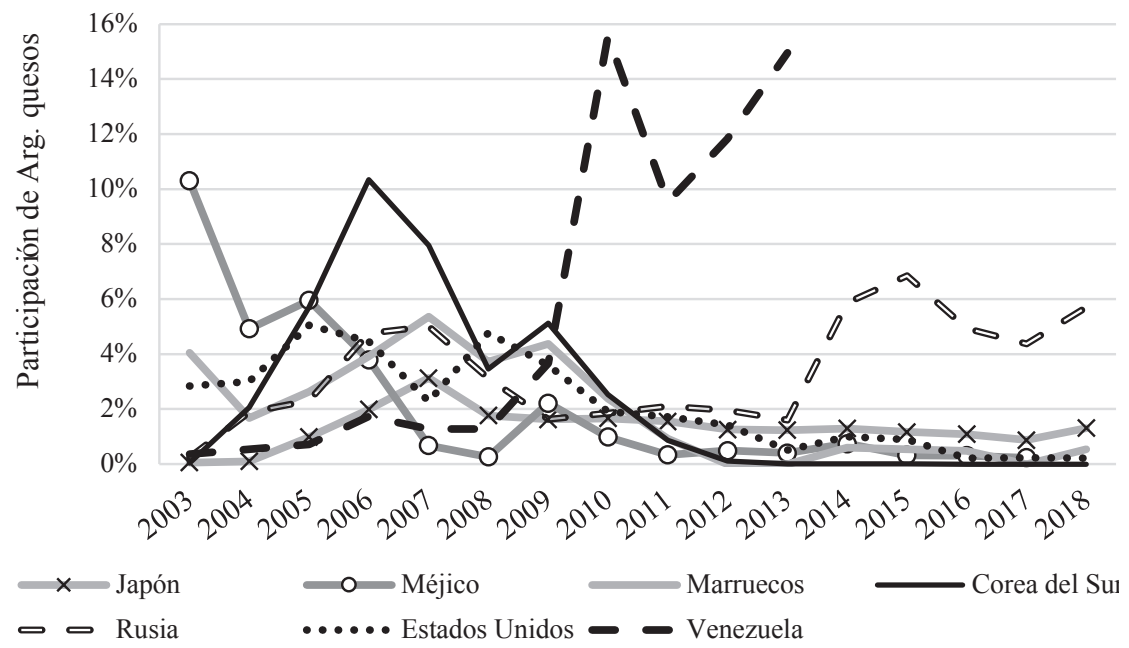

Fuente: elaboración propia con datos de Comtrade. 
Figura 2. Evolución de la participación de Argentina en los mercados importadores de LPE

(a)

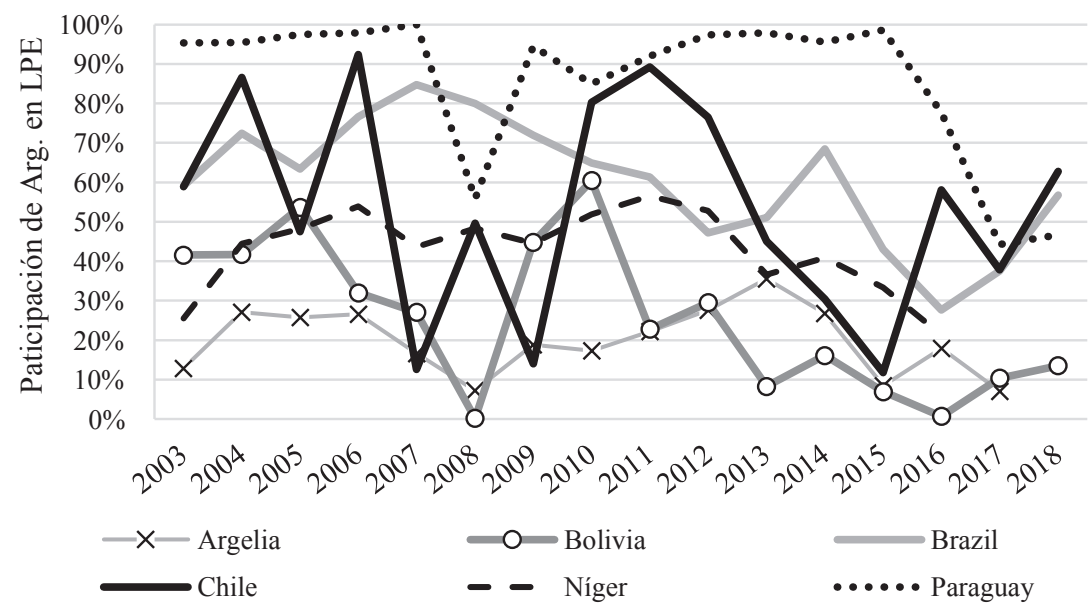

(b)

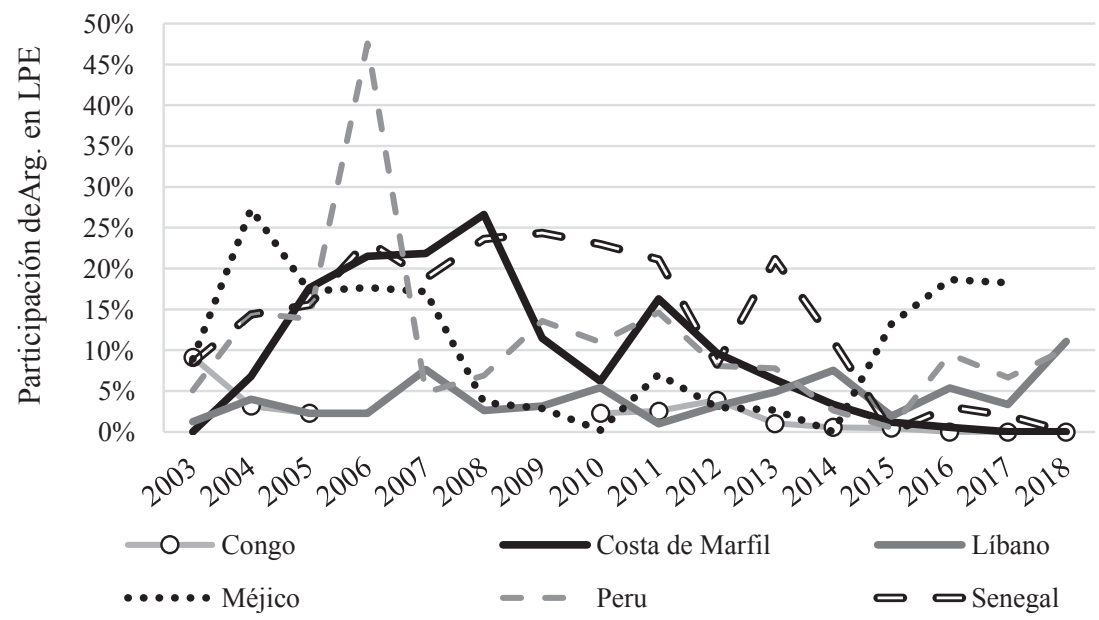

Fuente: elaboración propia con datos de Comtrade. 


\section{RESULTADOS}

IV.1. Ecuaciones de demanda de importaciones

En la estimación de los modelos de demanda se imponen dos restricciones derivadas de la teoría económica, a saber, homogeneidad y simetría. Para darle robustez a la interpretación de los parámetros estimados, es necesario contrastar empíricamente el cumplimiento de dichas hipótesis. Para ello contraponemos el modelo restringido con un modelo libre, donde tales restricciones no son impuestas. Específicamente, en la tabla 1 se muestra la prueba del cociente de verosimilitud con el objeto de analizar el cumplimiento de la hipótesis de homogeneidad y simetría en precios, bajo las dos especificaciones en función de la inclusión de los términos de interacción. De la misma se observa que la hipótesis de homogeneidad y simetría solo se rechaza para quesos y en el modelo que no diferencia entre grupos de países. Por lo tanto, podemos concluir que dichas hipótesis teóricas resultan razonables para imponer en el modelo econométrico de demanda. De todas maneras se presentan los resultados de ambos modelos (libre y restringido) a los fines de poder comparar los coeficientes de precios absolutos con los relativos (Argentina vs. Competidores).

Tabla 1. Prueba del cociente de verosimilitud modelo diferencial

\begin{tabular}{|c|c|c|c|c|}
\hline & \multicolumn{2}{|c|}{ Quesos } & \multicolumn{2}{|c|}{ Leche en Polvo } \\
\hline & $\begin{array}{c}\text { Sin } \\
\text { Interacción }\end{array}$ & $\begin{array}{c}\text { Con } \\
\text { interacción }\end{array}$ & $\begin{array}{c}\text { Sin } \\
\text { interacción }\end{array}$ & $\begin{array}{c}\text { Con } \\
\text { interacción }\end{array}$ \\
\hline LL Modelo Libre & 141.77 & 191.41 & 14.90 & 35.00 \\
\hline $\begin{array}{l}\text { LL Modelo } \\
\text { Restringido }\end{array}$ & 137.05 & 191.06 & 14.81 & 34.97 \\
\hline Estadístico & 9.44 & 0.68 & 0.18 & 0.07 \\
\hline$\chi_{005}^{2}[1]$ & 3.84 & 3.84 & 3.84 & 3.84 \\
\hline
\end{tabular}

Fuente: elaboración propia.

En la tabla 2, se presentan los resultados para la demanda de importaciones de quesos. De los valores del $R^{2}$ se observa que la bondad de ajuste para este tipo de modelos microeconométricos es más que razonable. El coeficiente del índice Divi- 
sia es positivo y estadísticamente significativo en todos los modelos, excepto para el caso del modelo libre con interacción. Estos resultados indican que la demanda por los quesos argentinos aumentaría ante un aumento en la propensión total a importar. Los coeficientes del precio-propio y relativo son todos estadísticamente significativos y negativos, como es de esperarse.

Tabla 2. Coeficientes estimados del modelo diferencial para quesos

\begin{tabular}{|c|c|c|c|c|}
\hline & \multicolumn{2}{|c|}{ Modelo Libre } & \multicolumn{2}{|c|}{ Modelo Restringido } \\
\hline & $\begin{array}{l}\text { Sin } \\
\text { interacción }\end{array}$ & $\begin{array}{c}\text { Con } \\
\text { interacción }\end{array}$ & $\begin{array}{l}\text { Sin } \\
\text { interacción }\end{array}$ & $\begin{array}{c}\text { Con } \\
\text { interacción }\end{array}$ \\
\hline$\Delta X_{j t}$ & $\begin{array}{c}0.39 * * * \\
(0.07)\end{array}$ & $\begin{array}{c}0.03 \\
(0.02)\end{array}$ & $\begin{array}{c}0.33 * * * \\
(0.06)\end{array}$ & $\begin{array}{c}0.02 * * \\
(0.01)\end{array}$ \\
\hline$\Delta p_{a, j t}$ & $\begin{array}{c}-0.14 * * * \\
(0.04)\end{array}$ & $\begin{array}{c}-0.04 * * * \\
(0.01)\end{array}$ & $\begin{array}{c}-0.15^{* * * *} \\
(0.04)\end{array}$ & $\begin{array}{c}-0.04 * * * \\
(0.01)\end{array}$ \\
\hline$\Delta p_{c, j t}$ & $\begin{array}{c}0.30 * * * \\
(0.09)\end{array}$ & $\begin{array}{c}0.047 * * \\
(0.02)\end{array}$ & & \\
\hline chile $_{j t}$ & $\begin{array}{c}-0.37 * * * \\
(0.03)\end{array}$ & $\begin{array}{c}-0.30 * * * \\
(0.03)\end{array}$ & $\begin{array}{c}-0.39 * * * \\
(0.03)\end{array}$ & $\begin{array}{c}-0.30 * * * \\
(0.03)\end{array}$ \\
\hline$P A_{j} \times \Delta X_{j t}$ & & $\begin{array}{c}0.55^{* * *} \\
(0.06)\end{array}$ & & $\begin{array}{c}0.55^{* * *} \\
(0.06)\end{array}$ \\
\hline$P A_{j} \times \Delta p_{a, j t}$ & & $\begin{array}{c}-0.18 * * * \\
(0.07)\end{array}$ & & $\begin{array}{c}-0.19 * * * \\
(0.07)\end{array}$ \\
\hline$P A_{j} \times \Delta p_{c, j t}$ & & $\begin{array}{c}0.23 * \\
(0.1188)\end{array}$ & & \\
\hline Constante & $\begin{array}{l}-0.01 \\
(0.01)\end{array}$ & $\begin{array}{l}-0.004 \\
(0.007)\end{array}$ & $\begin{array}{l}0.004 \\
(0.01)\end{array}$ & $\begin{array}{r}-0.002 \\
(0.01)\end{array}$ \\
\hline $\mathrm{N}^{\circ}$ Obs. & 180 & 180 & 180 & 180 \\
\hline$R^{2}$ & 0.46 & 0.69 & 0.43 & 0.69 \\
\hline $\begin{array}{l}\text { Homogeneidad } \\
\text { y Simetríab }\end{array}$ & $\begin{array}{c}F_{(1,175)}=4.7 \\
{[0.03]}\end{array}$ & $\begin{array}{c}F_{(1,172)}=0.3 \\
{[0.59]}\end{array}$ & & \\
\hline
\end{tabular}

Nota: $* * *$ p-valor $<0.01 ; * *$ p-valor $<0.05 ; *$ p-valor $<0.1$. Errores estándar robustos entre paréntesis. ${ }^{\text {a }}$ En el caso de los modelos restringidos $\Delta p_{a, j t}$ es el precio relativo Argentina-Competidores; ${ }^{\mathrm{b}}$ Valor $\mathrm{p}$ de la prueba $F$ entre corchetes.

Fuente: elaboración propia. 
Por su parte, los coeficientes del precio de los competidores son positivos y significativos, lo que indica que los quesos importados desde Argentina y desde otros destinos son sustitutos. La variable indicadora de la medida de salvaguardia impuesta por Chile es significativa a un nivel del $1 \%$, mostrando el impacto negativo de tal medida sobre la demanda de importaciones de quesos argentinos.

Las variables de interacción diferenciadas por grupo de países son, también, todas significativas, lo que da indicios de que el comportamiento de los demandantes cambia dependiendo de la cuota que tiene Argentina en dicho mercado. Específicamente se observa que en aquellos destinos donde Argentina tiene participación alta, lo efectos marginales sobre la demanda de importaciones de quesos argentinos son mayores (en valor absoluto). En la próxima sección del análisis de elasticidades, estos efectos cobrarán mayor riqueza en términos de la interpretación económica.

Tabla 3. Coeficientes estimados del modelo diferencial para leche en polvo entera

\begin{tabular}{|c|c|c|c|c|}
\hline & \multicolumn{2}{|c|}{ Modelo Libre } & \multicolumn{2}{|c|}{ Modelo Restringido ${ }^{\mathrm{a}}$} \\
\hline & $\begin{array}{l}\text { Sin } \\
\text { interacción }\end{array}$ & $\begin{array}{c}\text { Con } \\
\text { interacción }\end{array}$ & $\begin{array}{l}\text { Sin } \\
\text { interacción }\end{array}$ & $\begin{array}{c}\text { Con } \\
\text { interacción }\end{array}$ \\
\hline$\Delta X_{j t}$ & $\begin{array}{c}0.18^{* * *} \\
(0.06)\end{array}$ & $\begin{array}{c}0.05 * * * \\
(0.01)\end{array}$ & $\begin{array}{c}0.18^{* * *} \\
(0.06)\end{array}$ & $\begin{array}{c}0.06^{* * * *} \\
(0.02)\end{array}$ \\
\hline$\Delta p_{a, j t}$ & $\begin{array}{l}-0.16 \\
(0.13)\end{array}$ & $\begin{array}{c}0.07 \\
(0.05)\end{array}$ & $\begin{array}{l}-0.14 \\
(0.12)\end{array}$ & $\begin{array}{l}-0.21 \\
(0.13)\end{array}$ \\
\hline$\Delta p_{c, j t}$ & $\begin{array}{c}0.13 \\
(0.13)\end{array}$ & $\begin{array}{l}-0.08 \\
(0.06)\end{array}$ & & \\
\hline chile $_{j t}$ & $\begin{array}{c}-1.87 * * * \\
(0.14)\end{array}$ & $\begin{array}{c}-1.44 * * * \\
(0.17)\end{array}$ & $\begin{array}{c}-1.86^{* * * *} \\
(0.14)\end{array}$ & $\begin{array}{c}-1.42 * * * \\
(0.18)\end{array}$ \\
\hline$P A_{j} \times \Delta X_{j t}$ & & $\begin{array}{c}0.35 * * * \\
(0.06)\end{array}$ & & $\begin{array}{c}0.32 * * * \\
(0.07)\end{array}$ \\
\hline$P A_{j} \times \Delta p_{a, j t}$ & & $\begin{array}{c}-0.41 * * \\
(0.20)\end{array}$ & & $\begin{array}{l}-0.02 \\
(0.12)\end{array}$ \\
\hline$P A_{j} \times \Delta p_{c, j t}$ & & $\begin{array}{c}0.44 * * \\
(0.20)\end{array}$ & & \\
\hline
\end{tabular}




\begin{tabular}{lcccc} 
Constante & $\begin{array}{c}0.003 \\
(0.02)\end{array}$ & -0.003 & 0.003 & -0.002 \\
$\mathrm{~N}^{\circ}$ Obs. & 159 & $0.02)$ & $(0.02)$ & $(0.02)$ \\
$R^{2}$ & 0.47 & 0.59 & 159 & 159 \\
\hline $\begin{array}{l}\text { Homogeneidad } \\
\text { y Simetríab }\end{array}$ & $F_{(1,154)}=0.13$ & $F_{(1,172)}=0.03$ & & 0.47 \\
\hline
\end{tabular}

Nota: $* * *$ p-valor $<0.01 ; * *$ p-valor $<0.05 ; *$ p-valor $<0.1$. Errores estándar robustos entre paréntesis. ${ }^{\text {a }}$ En el caso de los modelos restringidos $\Delta p_{a, j t}$ es el precio relativo Argentina-Competidores; ${ }^{\mathrm{b}}$ Valor $\mathrm{p}$ de la prueba $F$ entre corchetes.

Fuente: elaboración propia.

En línea con la prueba del cociente de verosimilitud, también puede observarse a partir de la prueba $F$ el rechazo de la hipótesis de homogeneidad y simetría bajo la especificación sin interacciones, no así bajo el modelo que diferencia la respuesta de los países importadores.

Para la LPE, los resultados se presentan en la tabla 3. En este caso, los modelos también presentan una bondad de ajuste aceptable, considerando la imposición funcional rígida de estos modelos estructurales. El coeficiente del índice Divisia es estadísticamente significativo a un nivel del $1 \%$, mostrando que cuando las importaciones totales de cada importador aumentan, también lo hacen las importaciones de LPE de cada exportador (i. e. Argentina y sus competidores). Sin embargo, para el caso de los coeficientes de precios, estos no son estadísticamente significativos. Si bien, en general la estimación puntual de los mismos tiene el signo esperado, su variabilidad es alta, no pudiéndose rechazar la hipótesis de nulidad de los mismos. Por ende, de estas estimaciones puede inferirse que las importaciones de LPE son insensibles a los precios de cada uno de los exportadores.

Por su parte, el coeficiente de Chile es significativo y con el signo esperado, mostrando el deterioro de la posición competitiva de Argentina en el mercado chileno durante el período de salvaguardia. Por su parte, los efectos interacción son todos estadísticamente significativos en el modelo libre, no así en el modelo restringido, donde solo para el efecto de las importaciones totales en la participación marginal del exportador el coeficiente es significativo, mostrando que en aquellos mercados donde Argentina tiene una mayor participación, dicho efecto es mayor.

Para el caso de la demanda de importación de LPE, no existe evidencia estadística suficiente para rechazar las restricciones de homogeneidad y simetría 
tanto en el modelo con y sin interacción, lo que resulta consistente con lo expuesto a partir del test de cociente de verosimilitud.

En las próximas secciones mostramos los resultados de las elasticidades estimadas para quesos en primer lugar, y luego para LPE, para luego pasar a realizar un análisis del posicionamiento competitivo en ambos productos revelado por la demanda de los importadores.

\section{IV.2. Elasticidades de la demanda de importaciones de quesos}

En la tabla 4 se presentan las elasticidades estimadas en aquellos destinos donde Argentina posee una participación de mercado relativamente alta. En primer lugar, se puede observar que todas las elasticidades computadas son estadísticamente significativas a un nivel menor o igual al 5\%. Respecto a la elasticidad Divisia, se observa que la demanda es elástica, i. e. un aumento en el gasto total de importaciones de quesos genera un aumento más que proporcional en las cantidades demandadas de quesos de Argentina y de sus competidores, siendo mayor el cambio porcentual en estos últimos. Esto tiene sentido ya que Argentina posee una participación mayoritaria en dichos mercados, y de esta forma, la variación porcentual ante cambios en los gastos de importación debe ser relativamente menor al que experimentan sus competidores que tienen una participación más marginal.

Tabla 4. Elasticidades de la demanda de quesos de países de Participación Alta. Evaluadas en la mediana de las participaciones

\begin{tabular}{|c|c|c|c|c|}
\hline & \multirow{3}{*}{$\begin{array}{l}\text { Elasticidad } \\
\text { Divisa: } \hat{\eta}_{i, X}\end{array}$} & \multicolumn{3}{|c|}{ Elasticidades Precio } \\
\hline & & \multirow{2}{*}{ Propia: $\hat{\eta}_{i, i}$} & \multicolumn{2}{|c|}{ Cruzada: $\hat{\eta}_{i, j}$} \\
\hline & & & Argentina & Competidores \\
\hline \multirow[t]{2}{*}{ Argentina } & $1.54 * * *$ & $-0.58 * * *$ & & $0.72 * *$ \\
\hline & $(0.18)$ & $(0.17)$ & & $(0.32)$ \\
\hline \multirow[t]{2}{*}{ Competidores } & $2.28 * *$ & $-0.44 * *$ & $0.35 * * *$ & \\
\hline & $(0.11)$ & $(0.19)$ & $(0.11)$ & \\
\hline
\end{tabular}

Nota: $* * *$ p-valor $<0.01 ; * *$ p-valor $<0.05 ; *$ p-valor $<0.1$. Errores estándar calculados con el método Delta. Fuente: elaboración propia. 
De las elasticidades precio-propias, se observa para este grupo que los importadores de quesos son inelásticos a cambios en precios de cualquier origen. Sin embargo, responden más a los cambios en los precios de los quesos de Argentina: un aumento del $10 \%$ en el precio de los quesos argentinos reduciría su cantidad demandada en un 5.8\%, mientras que si el aumento fuera del precio de los competidores, la demanda de quesos con origen en estos se reduciría en un $4.4 \%$.

Por su parte, las elasticidades precio-cruzadas muestran que en estos mercados internacionales es más fácil sustituir los quesos de los competidores que los argentinos. Un aumento del 10\% del precio de los competidores, en promedio incrementaría la demanda de quesos argentinos en un $7.2 \%$. Si el precio del queso importado desde Argentina es el que aumenta en un 10\%, la demanda de quesos con origen en sus competidores aumentaría pero apenas en un 3.5\%. Esto se explica al considerar que en estos mercados importadores, la participación alta de Argentina también significaría una mayor dependencia del importador a los quesos provenientes de este país.

Las elasticidades de la demanda de importaciones en el grupo de países donde Argentina cuenta con una participación baja, se presentan en la tabla 5. Respecto al índice Divisia se observa que la elasticidad por los quesos argentinos es mayor que uno, pero la misma no es estadísticamente significativa por la variabilidad que presenta, mientras que la de los competidores es casi unitaria y estadísticamente significativa.

Ahora, respecto al precio propio, la demanda por quesos argentinos es elástica, mostrando que en promedio, un incremento del 10\% del precio de los quesos argentinos, disminuiría su cantidad demandada en aproximadamente un $25 \%$. Por el contrario, la demanda de quesos de los países competidores es inelástica, con una respuesta muy baja ante cambios en los precios de los mismos.

$\mathrm{Al}$ analizar las elasticidades-precio cruzadas, también se obtiene que la demanda de quesos argentinos es elástica, mostrando que si los precios de los competidores aumentaran en un $10 \%$, la cantidad demandada de quesos argentinos se incrementaría en casi un 30\%. Es decir, la respuesta de demanda sería mayor cuando se encarecen los quesos competidores que cuando se abarata el de Argentina. Por el contrario, existe poca sustitución hacia quesos de los países competidores cuando los precios de los quesos argentinos se incrementan. 
Tabla 5. Elasticidades de la demanda de quesos de países de Participación Baja. Evaluadas en la mediana de las participaciones

\begin{tabular}{|c|c|c|c|c|}
\hline & \multirow{3}{*}{$\begin{array}{l}\text { Elasticidad } \\
\text { Divisa: } \hat{\eta}_{i, X}\end{array}$} & \multicolumn{3}{|c|}{ Elasticidades Precio } \\
\hline & & \multirow{2}{*}{ Propia: $\hat{\eta}_{i, i}$} & \multicolumn{2}{|c|}{ Cruzada: $\hat{\eta}_{i, j}$} \\
\hline & & & Argentina & Competidores \\
\hline \multirow[t]{2}{*}{ Argentina } & 1.84 & $-2.50 * * *$ & & $2.99 * *$ \\
\hline & $(1.17)$ & $(0.60)$ & & $(1.34)$ \\
\hline \multirow[t]{2}{*}{ Competidores } & $0.99^{* * *}$ & $-0.05 * *$ & $0.04^{* * *}$ & \\
\hline & $(0.02)$ & $(0.02)$ & $(0.01)$ & \\
\hline
\end{tabular}

Nota: *** p-valor $<0.01 ; * *$ p-valor $<0.05 ; *$ p-valor $<0.1$. Errores estándar calculados con el método Delta.

Fuente: elaboración propia.

Al comparar estos resultados con las estimaciones realizadas por García Arancibia (2017) bajo el enfoque de la teoría del consumidor, se observa que las elasticidades, tanto propia como cruzadas, son similares para el caso de los países pertenecientes al grupo $P B$; esto es, superiores a 2. Específicamente, García Arancibia (2017) no separa al conjunto de importadores según su participación, pero en el agregado y bajo otro enfoque, encuentra estimaciones más coincidentes con las encontradas en el presente caso para destinos donde Argentina tiene baja participación. Sin embargo, estos destinos resultan ser importadores muy relevantes en el mercado mundial, por lo que tiene sentido que su respuesta predomine en el agregado de la demanda mundial. A su vez, en García Arancibia (2019), donde se estima la demanda de importaciones para el caso exclusivo de Chile (país incluido en $P A$ ), se encuentra que la elasticidad precio-propia compensada para los quesos argentinos es inelástica, aunque más alta que la encontrada en el presente trabajo. Para el caso de Brasil (García Arancibia \& Depetris Guiguet, 2020), las elasticidades precio-propias de los quesos argentinos ronda los valores de 1.3, por lo que en tal caso, si bien es elástica, no llega a los valores encontrados para los destinos agrupados en $P B$.

Si consideramos cada importador por separado, las elasticidades preciopropias de la demanda de quesos argentinos promediadas en el período se presentan en la figura 3. Se observa principalmente que en Japón y Marruecos las elasticidades son mayores que 2. Luego siguen Rusia, Estados Unidos y Corea del Sur, con elasticidades mayores a 1.5. Estos cinco destinos constituyen importantes 
importadores de quesos en el ámbito mundial, por lo que la mayor competencia por parte de los exportadores lácteos del mundo, se materializa en parte, en elasticidades precio-propias más altas. También puede observarse que la menor respuesta de la demanda se encuentra en los países sudamericanos, donde Argentina encuentra mayores ventajas comerciales, y con ello, un posicionamiento competitivo más firme en dichos mercados. Al comparar Chile con Brasil, los resultados encontrados son consistentes con la literatura empírica antes mencionadas; esto es, en Brasil la elasticidad precio-propia es menor que en Chile, lo que tiene sentido al considerar los competidores existentes en cada uno de dichos mercados. Mientras que en Brasil la competencia entre exportadores se concentra entre Argentina y Uruguay, en Chile los quesos argentinos también deben competir con aquellos provenientes de Estados Unidos, Nueva Zelanda y Europa.

Figura 3. Elasticidad precio-propia de la demanda de quesos argentinos por destino

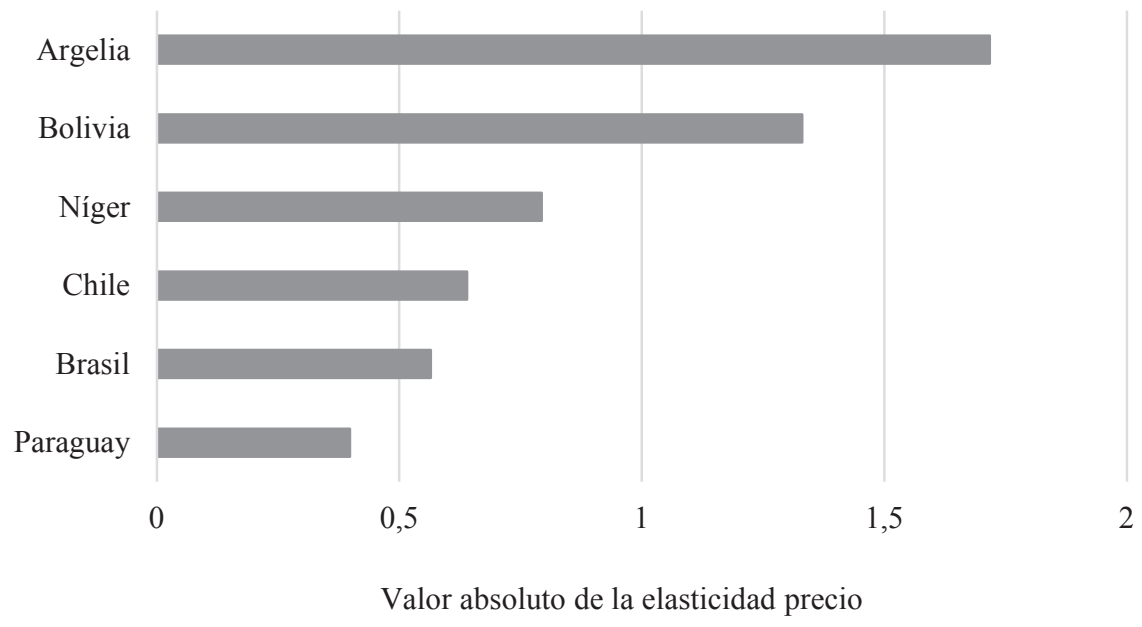

Fuente: elaboración propia.

IV.3. Elasticidades de la demanda de importaciones de leche en polvo

Para la LPE en los destinos agrupados en PA (tabla 6), se observa que la elasticidad Divisia para la LPE argentina es cercana a la unidad. Esto es, la cantidad demandada de LPE argentina cambia en la misma proporción que el 
cambio en el gasto total de importaciones de LPE por parte de estos países. Sin embargo, para el caso de sus competidores, el cambio es más que proporcional, mostrando que, en promedio, la cantidad demandada a los mismos se incrementaría en aproximadamente un $27 \%$ si el gasto de importaciones de LPE aumentara un $10 \%$. Esto significa una debilidad o desventaja competitiva de la LPE Argentina, a pesar de mantener en estos mercados una alta participación.

Para el caso de las elasticidades precio-propias, se observa que las mismas son estadísticamente significativas pero a un nivel del 10\%, e inelástica, lo que se condice con las estimaciones realizadas en otros trabajos (García Arancibia 2017; $2019 ; 2020)$. Un aumento del $10 \%$ del precio de la LPE argentina disminuiría, en promedio, la cantidad demandada por estos importadores en un $8.2 \%$. Para los competidores, el efecto precio-propio es menor, mostrando que en el caso de una variación semejante de precios, la reducción en la cantidad demandada sería de $6.2 \%$. Nuevamente esto significa una desventaja para Argentina en términos competitivos. Sin embargo, las elasticidades precio-cruzadas (significativas también al nivel del 10\%) muestran que si los competidores aumentan su precio en un $10 \%$, la cantidad demandada de LPE argentina se incrementaría en promedio en casi un 9\%; mientras que si fueran los precios de la LPE argentina los que aumentaran de esta manera, el incremento de cantidad de LPE de los otros orígenes sería de casi el 6\%. En tal sentido, Argentina muestra un mejor posicionamiento en términos de la capacidad de sustituir LPE cuando aumentan los precios de la competencia.

Tabla 6. Elasticidades de la demanda de leche en polvo de países de Participación Alta. Evaluadas en la mediana de las participaciones

\begin{tabular}{|c|c|c|c|c|}
\hline & \multirow{3}{*}{$\begin{array}{l}\text { Elasticidad } \\
\text { Divisa: } \hat{\eta}_{i, X}\end{array}$} & \multicolumn{3}{|c|}{ Elasticidades Precio } \\
\hline & & \multirow{2}{*}{ Propia: $\hat{\eta}_{i, i}$} & \multicolumn{2}{|c|}{ Cruzada: $\hat{\eta}_{i, j}$} \\
\hline & & & Argentina & Competidores \\
\hline \multirow[t]{2}{*}{ Argentina } & $0.96 * * *$ & $-0.82 *$ & & $0.87 *$ \\
\hline & $(0.16)$ & $(0.47)$ & & $(0.45)$ \\
\hline \multirow[t]{2}{*}{ Competidores } & $2.74 * * *$ & $-0.62 *$ & $0.59 *$ & \\
\hline & $(0.11)$ & $(0.32)$ & $(0.34)$ & \\
\hline
\end{tabular}

Nota: *** p-valor $<0.01 ; * *$ p-valor $<0.05 ; *$ p-valor $<0.1$. Errores estándar calculados con el método Delta.

Fuente: elaboración propia. 
Para el caso de la demanda de LPE en los destinos agrupados en $P B$, solo las elasticidades Divisia resultan estadísticamente significativas. Los resultados muestran que tanto para la LPE argentina como la de los países competidores, los cambios en la cantidad demandada son proporcionales al cambio en el gasto total de importaciones en LPE, i. e. las elasticidades Divisia son casi unitarias. Para el caso de las elasticidades precio, no pueden derivarse conclusiones robustas debido a la alta variabilidad que presentan las mismas. En valor absoluto, las elasticidades precio de la LPE argentina resultan mayores, lo cual tendría sentido al considerar la menor participación en tales mercados. No obstante, dada la poca precisión de tales elasticidades, nos limitaremos de aquí en adelante a comentar e interpretar solo los resultados para la LPE en países donde Argentina tiene mayor participación de mercado.

Tabla 7. Elasticidades de la demanda de leche en polvo de países de Participación Baja. Evaluadas en la mediana de las participaciones

\begin{tabular}{|c|c|c|c|c|}
\hline & \multirow{3}{*}{$\begin{array}{l}\text { Elasticidad } \\
\text { Divisa: } \hat{\eta}_{i, X}\end{array}$} & \multicolumn{3}{|c|}{ Elasticidades Precio } \\
\hline & & \multirow{2}{*}{ Propia: $\hat{\eta}_{i, i}$} & \multicolumn{2}{|c|}{ Cruzada: $\hat{\eta}_{i, j}$} \\
\hline & & & Argentina & Competidores \\
\hline \multirow[t]{2}{*}{ Argentina } & $0.96 * * *$ & 1.42 & & -1.55 \\
\hline & $(0.23)$ & $(0.92)$ & & $(1.25)$ \\
\hline \multirow[t]{2}{*}{ Competidores } & $1.00 * * *$ & 0.08 & -0.07 & \\
\hline & $(0.01)$ & $(0.08)$ & $(0.05)$ & \\
\hline
\end{tabular}

Nota: *** p-valor $<0.01 ; * *$ p-valor $<0.05 ; *$ p-valor $<0.1$. Errores estándar calculados con el método Delta.

Fuente: elaboración propia.

En este conjunto de países, para los cuales la elasticidad precio-propia cobra mayor sentido (figura 4), puede observarse que en Argelia tal elasticidad es mayor a la unidad. Argelia, que es uno de los principales compradores mundiales, es un mercado de importaciones lácteas con muchos oferentes, pero concentrados principalmente entre Nueva Zelanda, Francia y Argentina. Dado este nivel de competencia, es de esperar elasticidades precio-propias mayores en este mercado. También se observa que en Bolivia, a pesar de su cercanía con Argentina, la demanda es elástica. Esto quizás responde más a una capacidad de sustitución con otros productos $(e . g$. leche fluida doméstica e importada) que al nivel de atomicidad que puede existir en tal mercado. Las menores elasticidades precio-propias se encuentran para Chile, Brasil y Paraguay, coincidiendo con valores cercanos a los de quesos. 
Figura 4. Elasticidad precio-propia de la demanda de leche en polvo argentina.

Países de Participación Alta

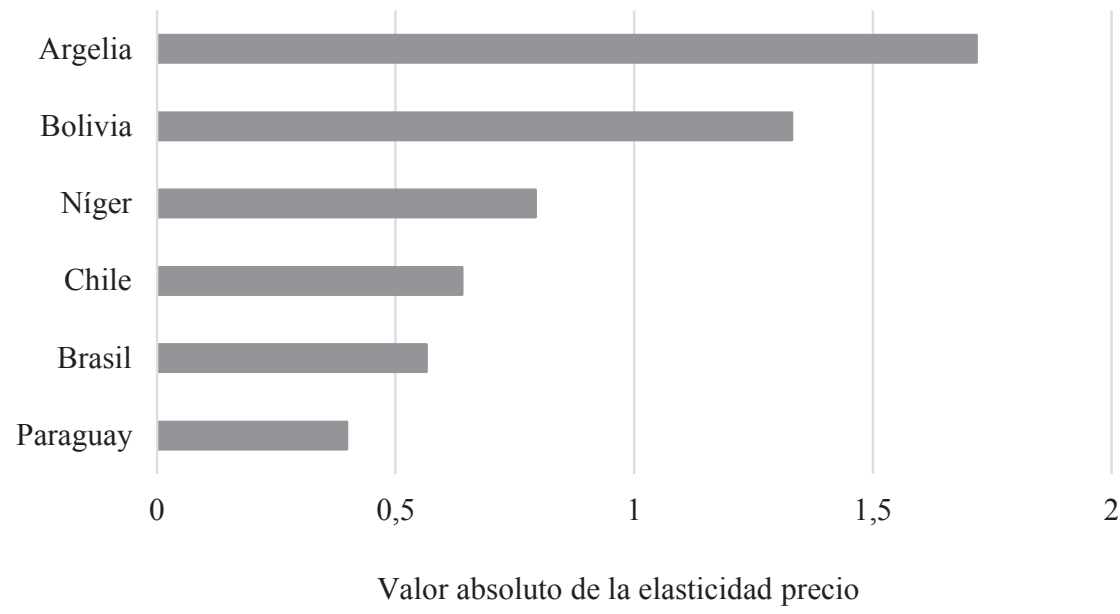

Fuente: elaboración propia.

Por ende, estos resultados mostrarían que la cercanía y, más precisamente su asociación en el marco Mercosur, le otorgan a Argentina cierta estabilidad en términos de competitividad vía variaciones de los precios en el mercado internacional. Tal resultado se verá reforzado en la próxima sección donde mostramos los índices de competitividad construidos usando tales elasticidades.

IV.4. Análisis de la competitividad de las exportaciones de quesos y leche en polvo

Como se señaló en la sección III.3, con las elasticidades precio-propias estimadas es posible construir dos indicadores de competitividad: uno específico para Argentina, donde se pondera el valor absoluto de la elasticidad por la participación del país en cierto mercado importador (ecuación (11), y uno general del grado de competitividad que caracteriza al mercado (y no al exportador específico), donde la elasticidad promedio del mismo se pondera por un índice de concentración de los exportadores.

En la figura 5 se presenta el índice de competitividad para quesos en cada mercado importador considerado. Se observa que en Uruguay, a pesar de ser un 
competidor en la región, Argentina presenta el mayor nivel de posicionamiento competitivo. Sin embargo, como en el modelo no se tiene en cuenta la producción doméstica, y solo se compara entre el 'insumo' importado, esta medida sería acotada en tal sentido, al considerar que Uruguay representa un mercado pequeño para las importaciones lácteas. Luego, en orden de importancia, sigue Brasil que si bien tiene una importante producción doméstica, el mercado importador es muy relevante. Aquí Argentina presenta un destacable posicionamiento competitivo, como también en Chile donde además es un mercado en el que participan importaciones relevantes de países como Estados Unidos, Nueva Zelanda y países de la Unión Europea.

Figura 5. Índice de competitividad de las exportaciones argentinas de quesos por destino

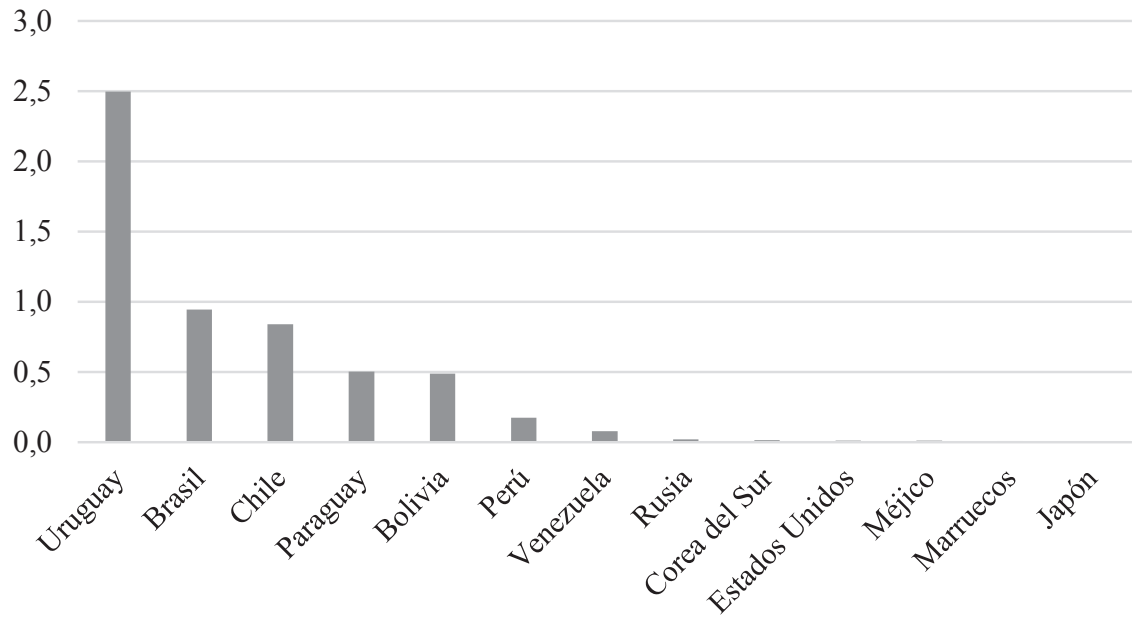

Fuente: elaboración propia.

Claramente, el mayor posicionamiento competitivo se encuentra en las exportaciones que van hacia la región. Fuera de América del Sur, el mejor posicionamiento competitivo se revela en Rusia, seguido de Corea del Sur, Estados Unidos y México. Sin embargo, el valor del indicador es sustancialmente menor al revelado en los países sudamericanos, y en particular, en los asociados al Mercosur.

En la figura 6 se muestra la evolución del índice general de competitividad. Este índice busca mostrar las posibilidades competitivas de Argentina de manera agregada para cada grupo de países. En primer lugar, podemos apreciar que las 
posibilidades competitivas para las exportaciones de quesos son mayores en los países donde Argentina tiene mayor participación, lo que se condice con mercados más concentrados e inelásticos. Por ende, tienen una mayor posibilidad de mantener su posicionamiento competitivo a pesar de los cambios en los precios relativos. En cuanto a su evolución, se observa que desde 2003 hasta 2006, para ambos grupos de países la competitividad en términos del $I C G$ aumentó. Luego de caer en 2007, para los destinos agrupados en $P A$ el nivel de potencial competitivo creció levemente y se mantuvo relativamente constante. Sin embargo, para los países agrupados en $P B$, el $I C G$ ha mostrado una tendencia decreciente, lo que podría deberse a la mayor competencia existente en los mismos por el crecimiento de potenciales exportadores, y por ende, a una caída en el nivel de concentración de los mismos. Por lo tanto, podemos concluir que las posibilidades competitivas de Argentina en mercados más distantes se fueron deteriorando con el tiempo, lo que podría ser un freno a su crecimiento en términos de ganar participación en tales mercados.

Figura 6. Índice de competitividad general de las exportaciones argentinas de quesos

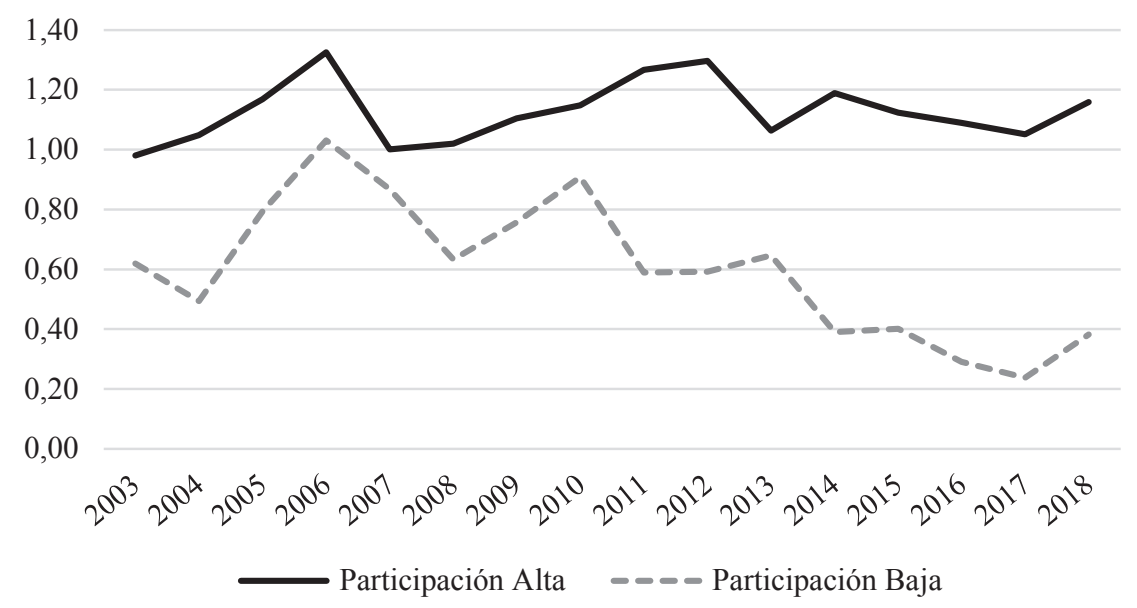

Fuente: elaboración propia.

Para el caso de la LPE, solo analizamos al grupo conformado por países donde Argentina tiene mayor participación $(P A)$, dado que las estimaciones de elasticidad para el grupo $P B$ no son precisas a los fines de obtener una interpretación robusta de los resultados. En la figura 7, se puede ver que la mayor competitividad 
en LPE, Argentina la tiene en Paraguay, donde básicamente tiene más del $80 \%$ del mercado. Luego en niveles similares le siguen Brasil y Chile; posteriormente, en Níger y Bolivia, y por último en Argelia. Las conclusiones obtenidas con el $I C$ son similares a aquellas a las que pudimos arribar simplemente con las elasticidades. De hecho el ranking de competitividad arrojado por el $I C$ es equivalente al que tendríamos con el recíproco del valor absoluto de la elasticidad.

Figura 7. Índice de competitividad de las exportaciones argentinas de leche en polvo por destino. Países de Participación Alta

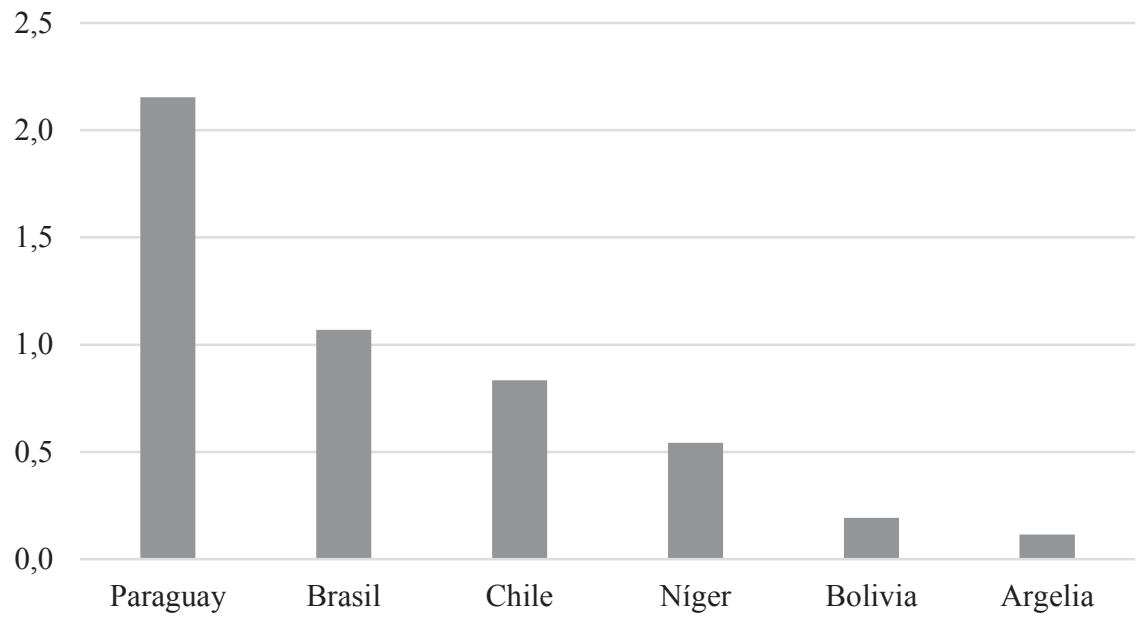

Fuente: elaboración propia.

En términos generales, para estos países, el $I C G$ nos revela que desde 2010 el potencial competitivo ha ido decayendo continuamente (figura 7). Hacia finales de 2018, hay una leve recuperación pero lejos está de los niveles relevados entre 2003 y 2006. Por ende, contrariamente a lo que se observó en el mercado internacional de quesos, donde las posibilidades competitivas de los mercados predominantes para Argentina ha podido mantenerse e incluso crecer en el tiempo, para la LPE el escenario pareciera ser más complicado. 
Figura 8. Índice de competitividad general de las exportaciones argentinas de leche en polvo. Países de Participación Alta

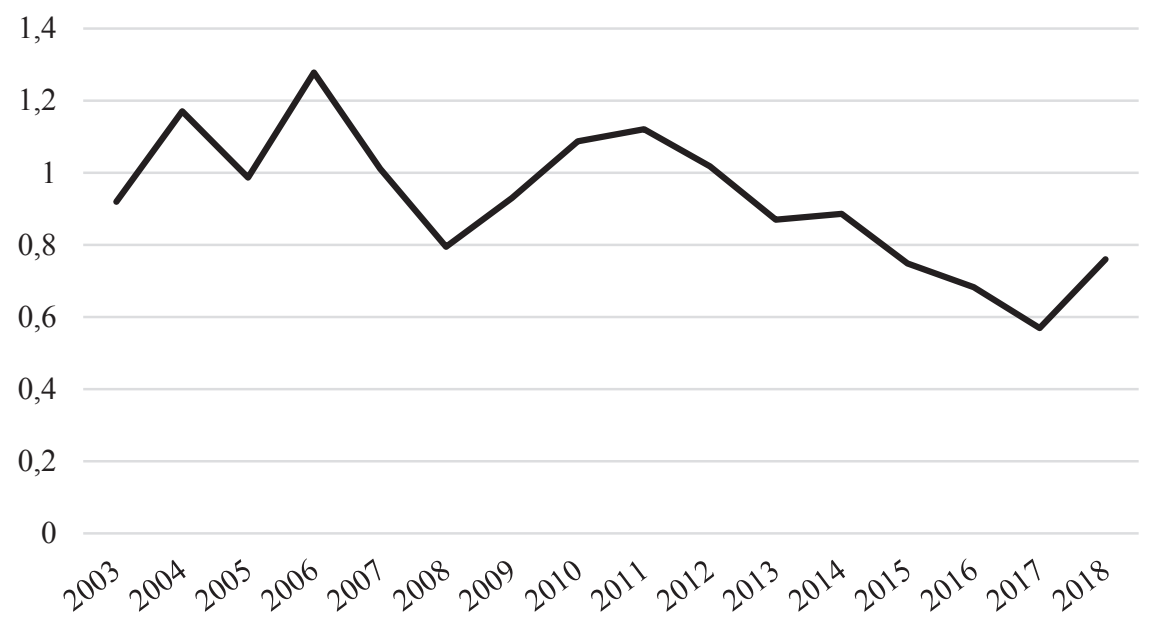

Fuente: elaboración propia.

\section{CONCLUSIONES}

Las exportaciones lácteas de Argentina han mostrado una tendencia relativamente creciente en las últimas dos décadas, con altibajos importantes producto de diversos condicionantes tanto a nivel nacional como internacional. En este contexto, y dada la relevancia que posee la demanda internacional de quesos y leche en polvo para el desempeño global del sector, se buscó conocer las elasticidades de la demanda de los principales países importadores de estos productos.

Para ello, se propuso un modelo en el marco de la teoría microeconómica del productor basada en el enfoque diferencial y adaptado para datos de panel. La especificación adoptada permitió diferenciar la respuesta de los países importadores en dos grupos, en función de la participación promedio de Argentina en dichos mercados. Además, las elasticidades calculadas sirvieron de base para el análisis del posicionamiento competitivo de ambos productos en los mercados de importación.

Los resultados mostraron que la demanda de importaciones de quesos argentinos resulta inelástica en aquellos destinos donde la Argentina tiene una participación alta, principalmente en los países latinoamericanos. De esta forma, 
la proximidad y las mayores ventajas comerciales presentes en el marco Mercosur resultan factores positivos para las exportaciones de quesos, que se reflejan en la respuesta a precios de estos importadores. En estos mismos países, la elasticidad gasto de la demanda de quesos de Argentina y de sus competidores es elástica, siendo mayor en los últimos. El buen posicionamiento de Argentina en estos mercados también se evidencia a partir de las elasticidades precio-cruzadas, ya que indican que es más fácil sustituir los quesos de los competidores que los argentinos ante variaciones en los precios de importación. En cambio, en países donde Argentina posee una participación baja, la demanda por quesos argentinos resulta elástica, mientras que la de los países competidores, inelástica.

Por otro lado, las elasticidades gastos y precio-propias obtenidas en LPE muestran una desventaja competitiva de la Argentina respecto a sus competidores, incluso en los mercados con una alta participación. En estos, solo se encuentra un mejor posicionamiento para sustituir LPE cuando aumentan los precios de la competencia, y no se han encontrado resultados robustos en los modelos donde Argentina tiene una participación baja.

De los indicadores de competitividad calculados, las exportaciones de quesos de Argentina revelaron un mayor posicionamiento competitivo en destinos pertenecientes a la región, que ha logrado mantener, si bien con altibajos, durante el período analizado. Sin embargo, y para este mismo producto, se evidencia un marcado deterioro en mercados más distantes. Por su parte, las posibilidades competitivas de Argentina en los principales mercados de LPE se han deteriorado desde el año 2006. Esto amerita un análisis de mayor profundidad con el objeto de visibilizar aquellos factores que han incidido sobre este desempeño, dada la importancia de este producto en las exportaciones del sector lácteo.

Entre las posibles extensiones que enriquecerían el análisis, puede mencionarse la inclusión de la producción doméstica de los países importadores dentro del sistema de demanda a estimar. En especial para aquellos países donde la misma es relevante, como ser en los sudamericanos donde Argentina posee un fuerte peso en el mercado de lácteos importados. Con tal extensión, se podría determinar cuáles son las posibilidades de sustitución de los lácteos importados como consecuencia del continuo crecimiento en la producción láctea doméstica, lo que precisamente ocurre en países como Brasil y Chile. Este conocimiento puede ser de gran importancia para la futura competitividad internacional del sector lácteo argentino, dada la alta dependencia que se tiene de las importaciones de estos países, junto con la mayor dificultad y presión competitiva que se encuentran en los mercados más distantes. 


\section{REFERENCIAS}

Armington, P. (1969). A Theory of Demand for Products Distinguished by Place of Production (Une théorie de la demande de produits différenciés d'après leur origine) (Una teoría de la demanda de productos distinguiéndolos según el lugar de producción). Staff Papers (International Monetary Fund), 16(1), 159-178. doi: $10.2307 / 3866403$

Coronel, M., García Arancibia, R., \& Vicentin Masaro, J. (2014). Efecto del Tipo de Cambio Real sobre la Oferta de Lácteos Santafesina. Revista Visión de Futuro 18(1), 193-212.

Coronel, M., García Arancibia, R., \& Vicentin Masaro, J. (2020). Demanda Externa y Competitividad de las Exportaciones Argentinas de Quesos y Leche en Polvo en los Principales Mercados Importadores. Trabajo presentado en $L I$ Reunión Anual de la Asociación Argentina de Economía Agraria (AAEA) con modalidad virtual.

Depetris Guiguet, E., García Arancibia, R., \& Rossini, G. (2009). Desempeño Competitivo de Argentina y Uruguay en Leche en Polvo desde su Integración en el Mercosur. Problemas de Desarrollo, Revista Latinoamericana de Economía, UNAM-México, 40(157). doi: http://dx.doi.org/10.22201/ iiec.20078951e.2009.157.7762

Depetris Guiguet, E., Rossini, G., García Arancibia, R., \& Vicentin Masaro, J. (2011) Competitividad del Complejo Lácteo Santafesino. Período 20002009. Santa Fe: FCE-UNL.

Depetris Guiguet, E., García Arancibia, R., \& Rossini, G. (2012) Competitividad de las Exportaciones Argentinas de Quesos desde la implementación del Mercosur. Revista Argentina de Lactología, 27(1), 9-21.

Depetris Guiguet, E., Rossini, G., García Arancibia, R., Vicentin Masaro, J., \& Coronel, M. (2013). Cambios y tendencias en las políticas lecheras de los principales participantes del mercado internacional. Santa Fe: IECAL; FCE; UNL.

García Arancibia, R. (2017). Elasticidades de la demanda mundial de lácteos argentinos y su posicionamiento competitivo. Revista de Economía del Rosario, 20(2), 275-306. doi: https://doi.org/10.12804/revistas.urosario. edu.co/economia/a.6457

García Arancibia, R. (2019). Import Demand for Dairy Products in Chile and Competition among Exporting Countries: The case of Milk Powder and Cheese. Economia Agro-Alimentare/Food Economy, 21(1), 101-128. doi: 10.3280/ECAG2019-001006

García Arancibia, R., Depetris Guiguet, E., \& Rossini, G (2015). Elasticidades de la Demanda Mundial de Quesos Argentinos: Un Enfoque Uniecuacional 
con Datos de Panel. Anales de la XLVI Reunión Anual de la Asociación Argentina de Economía Agraria (AAEA). Tandil, Buenos Aires.

García Arancibia, R., Depetris Guiguet, E., Vicentin Masaro, J., \& Rossini, G. (2013). Factores Determinantes de la Oferta Exportadora Láctea Santafesina. SaberES, 5(1), 71-85. doi: https://doi.org/10.35305/s.v0i5.89

García Arancibia, R., \& Depetris Guiguet, E. (2020). Brazilian Import Demand of Dairy Products with Emphasis in the Mercosul. Nova Economia, 30(2), 551-577. doi: https://doi.org/10.1590/0103-6351/4946

Kaiser, H. M. \& Suzuki, N. (2006). New Empirical Industrial Organization and the Food System. New York: Peter Lang Publishing.

Koo, W. W., Mao, W., \& Sakurai, T. (2001). Wheat demand in Japanese flour milling industry: a production theory approach. Agricultural economics, 24(2), 167-178. doi: https://doi.org/10.1016/S0169-5150(00)00062-1

Laitinen, K. (1980). The theory of the multiproduct firm. New York: North-Holland Publishing Company.

Laitinen, K., \& Theil, H. (1978). Supply and demand of the multiproduct firm. European Economic Review, 11(2), 107-154. doi: http://dx.doi. org/10.1016/0014-2921(78)90031-4

Lema, D., Galetto, A., \& Loyato, V. (2005). Estimación de la elasticidad de la demanda de quesos por segmentos y niveles de marcas mediante la utilización de datos de scanner (INTA Documento de Trabajo No. 33). Recuperado de http://hdl.handle.net/20.500.12123/5455

Muhammad, A. (2007). The impact of increasing non-agricultural market access on EU demand for imported fish: implications for Lake Victoria chilled fillet exports. European Review of Agricultural Economics 34(4), 461-477. doi: https://doi.org/10.1093/erae/jbm034

Muhammad, A. (2009). Would African countries benefit from the termination of Kenya's Economic Partnership Agreement (EPA) with the EU? An analysis of EU demand for imported roses. Journal of Agricultural Economics, 60(1), 220-238. doi: https://doi.org/10.1111/j.1477-9552.2008.00169.x

Muhammad, A., Amponsah, W. A., \& Dennis, J. H. (2010). The impact of preferential trade arrangements on EU imports from developing countries: The case of fresh cut flowers. Applied Economic Perspectives and Policy, 32(2), 254-274. doi: https://doi.org/10.1093/aepp/ppp008

Muhammad, A., Jones, K. G., \& Hahn, W. F. (2007). The impact of domestic and import prices on US lamb imports: A production system approach. Agricultural and Resource Economics Review, 36(2), 293-303. doi: 10.22004/ag.econ.44704 
Observatorio de la Cadena Láctea Argentina-OCLA. (2020). Consultado el 01/04/2020, en: https://www.ocla.org.ar/contents/newschart/ portfolio/?categoryid $=6$

Rossini, G., Guiguet, E. D., \& Villanueva, R. (2008). Estimación de Elasticidades de Diferentes Productos Lácteos en las Provincias de Santa Fe y Entre Ríos. Revista de Economía y Estadística, 46(1), 31-44.

Rossini, G., Vicentin Masaro, J., García Arancibia, R., \& Coronel, M. (2013). Transmisiones de precios en el sector lácteo: el análisis del comportamiento de precios de exportación y el recibido por los productores. Revista de la FAVE. Ciencias Agrarias, 12(1), 45-54. doi: https://doi.org/10.14409/ fa.v12i1/2.5117.

Vicentin Masaro, J., Depetris, E., García Arancibia, R., \& Rossini, G. (2013). Retrasos en la transmisión de precios de exportación entre los principales productos lácteos santafesinos: leche en polvo entera y quesos. Revista Ciencias Económicas, 10(2), 11-21. doi: https://doi.org/10.14409/ ce.v2i15.4264

Wang, X., \& Reed, M. (2014). Estimation of U.S. Demand for Imported Shrimp by Country: A Two-stage Differential Production Approach. Selected Paper prepared for presentation at the Southern Agricultural Economics Association Annual Meeting, February 1-4, Dallas, Texas. doi: 10.22004/ ag.econ.162459

Washington, A. A., \& Kilmer, R. L. (2002a). The production theory approach to import demand analysis: A comparison of the Rotterdam model and the differential production approach. Journal of Agricultural and Applied Economics, 34(3), 431-443. doi: https://doi.org/10.1017/ S1074070800009226

Washington, A. A., \& Kilmer, R. L. (2002b). The Derived Demand for Imported Cheese into Japan: A Two-Stage Differential Production Approach. Paper Presented at the AAEA Meeting, Long Beach, California. doi: 10.22004/ ag.econ.19769

Washington, A., Yigletu, A., \& Andrews, D. (2012). The derived demand for imported wheat in Ghana. Southwestern Economic Proceedings, 29(1), 49-58.

(C) 2022 por los autores; licencia no exclusiva otorgada a la revista Estudios económicos. Este artículo es de acceso abierto y distribuido bajo los términos y condiciones de una licencia Atribución-No Comercial 4.0 Internacional (CC BY-NC 4.0) de Creative Commons. Para ver una copia de esta licencia, visite http://creativecommons.org/licenses/by-nc/4.0 
